\title{
Experimental investigation of corrosion damage on reinforced concrete beams to correlate crack width and mass loss
}

\author{
H. Nasser, C. Van Steen, R. Vrijdaghs, L. Vandewalle, E. Verstrynge \\ Katholieke Universiteit Leuven (KU Leuven), Leuven, Belgium
}

There is an increasing number of existing reinforced concrete structures deteriorated by chloride-induced corrosion. Quantifying the severity of the corrosion damage through different inspection measurements is vital to assess the damage level of the structure. Because corrosion cracking is a visible damage on the surface, it can provide engineers with important information regarding the damage state as well as the mass loss level. In order to study the cracking as an indicator of corrosion damage, this paper presents an accelerated corrosion experiment on singly reinforced beams with one ribbed or smooth rebar. The results clearly show distinct cracking ranges as a function of the corrosion damage. They also show a good linear relation between the cracking and the mass loss level. Finally, it is observed that the different mass loss prediction models found in the literature were not fully adequate to predict the results of the current experiment.

\section{INTRODUCTION}

Reinforced concrete (RC) is a widely used construction material, however, RC infrastructures show early signs of deterioration before reaching their design service life due to durability issues related to the concrete microstructure. Chloride-induced corrosion is considered to be one of the major durability problems that causes serviceability related issues such as the formation of rust spots, cracking and spalling. Moreover, it causes reduction in the ultimate strength of the RC member and eventually could lead to collapse of the structure. Therefore, it is important to classify the damage level based on inspection data and be able to quantify the residual structural capacity.

Measuring the damage is done by different inspection tools which provide information on the presence of corrosion, via half-cell potantial and resistivity measurements, and its progress via the corrosion rate. Chloride content and penetration depth along with cracking are also important parameters used to further verify the presence of corrosion and its severity. By obtaining this data, some manuals offer averaged damage indices that assist in classifying the inspected component into damage levels (CONTECVET ). However, their cracking ranges are based on serviceability limit state criteria rather than in relation to the corrosion progress which is reflected by the mass loss. Because in existing concrete structures, cover cracking is already visible and can be measured with high level of certainty, basing the damage classification on corrosion crack width is efficient in an inspection framework.

Corrosion rate measurements reflect the progress of the damage which can give information regarding the time to cover cracking and the severity of the corrosion progress. However, this classification reflects the rate of progress rather than the current state of the structure. Moreover, because corosion rate is very sensitive to environmental factors and repetitive measurements are normally recommended, high uncertainty is exhibited in interpreting the results.

In an inspection-based framework, the ability to predict the residual structural capacity depends on proper quantification of the mass loss (Nasser et al. 2019) and on relating it to other structural damage such as the bond loss (Van Steen et al. 2019). Many authors investigated damage relations which relate the crack width to the mass loss (Vidal et al. 2004, Rodriguez et al. 2006). Yet, it is seen that there is a great difference in defining the relations which has been treated by taking into account some of the factors that affect the cover cracking such as the tensile strength and the cover-diameter ratio (Andrade et al. 2016, Khan et al. 2014). However, the adequacy of the prediction of these models for on-site inspection as well as for accelerated corrosion experiments is still a question. On one hand, the accelereted corrosion experiments might lead to different corrosion products and pressure build up which is different than the natural corrosion process (Zhang, Weiping et al. 2019). On the other hand, the 
different accelerated corrosion set-ups might also yield different cracking behaviour due to the location of the cathodes and degree of immersion in the solution (Malumbela et al. 2012).

The present paper presents an accelerated corrosion experiment on singly reinforced beams with one ribbed or smooth rebar. Firstly, cracking ranges for single reinforced beams are defined. Secondly, the cross-section loss is assessed to study the formation of pits and their variation. Thirdly, an empirical relation linking the crack width to the section loss is developed which is compared to other relations in the literature in an attempt to investigate their reliability in prediction.

\section{EXPERIMENTAL SET-UPS}

\subsection{Preparation of samples}

The beams were prepared using the composition shown in Table 1. The section dimensions were $150 \times 200 \mathrm{~mm}$, which were reinforced with one $14 \mathrm{~mm}$ ribbed or smooth bar in the tensile zone. A cover of $30 \mathrm{~mm}$ was chosen and the length of the sample was $1.8 \mathrm{~m}$. In total, 17 beams were made from nine concrete batches where one batch produced two beams, 3 or 6 cubes (depending on whether the beams are to be corroded or not), and 3 prisms. Nine beams were reinforced with one ribbed rebar, of which three were non-corroded, and eight beams were reinforced with a smooth bar of which two were non-corroded.

Table 1. Concrete composition used for the experiments.

\begin{tabular}{lll}
\hline Aggregates & 1270 & $\mathrm{~kg} / \mathrm{m}^{3}$ \\
Sand & 620 & $\mathrm{~kg} / \mathrm{m}^{3}$ \\
CEM I 42.5 N & 350 & $\mathrm{~kg} / \mathrm{m}^{3}$ \\
Water & 164 & $\mathrm{~kg} / \mathrm{m}^{3}$ \\
$\mathrm{NaCl}$ & 7 & $\mathrm{~kg} / \mathrm{m}^{3}$ \\
\hline
\end{tabular}

Casting the samples was done in wooden moulds in the position shown in Figure 1 (left/middle) where the steel bars were positioned at the top. This helped to control the deflection of the bar during the pouring so that a uniform cover could be maintained. Moreover, $10 \mathrm{~cm}$ of the bar protruded outside of the
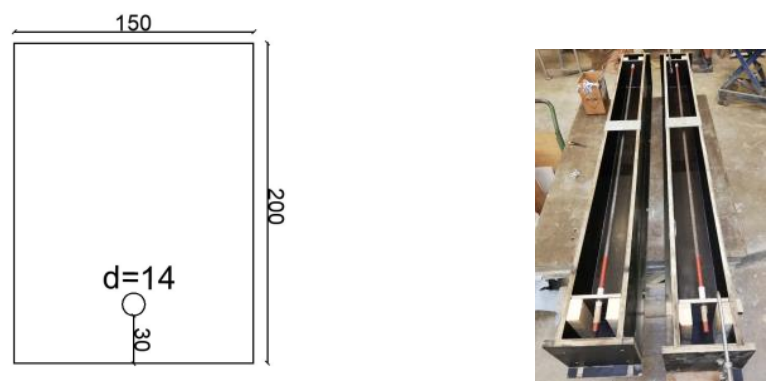

concrete from each side, which would later serve to connect it to an electrical power supply. Finally, 25 $\mathrm{cm}$ from each side of the rebar was painted with a red anti-rust primer so that the contamination of these parts would be prevented and only a total of $1.5 \mathrm{~m}$ would corrode.

\subsection{Accelerated corrosion}

Accelerating the corrosion reaction is done by manipulating the factors that affect its kinetics. It can be done by increasing the temperature or the concentration of salts to simulate the corrosion process naturally (Zhu et al. 2014). Moreover, anodic polarization is also a popular method used for corrosion studies on RC beams where a DC current is applied connecting the rebar (anode) to a stainless steel plate (cathode) in a salt solution.

The choice of the concentration of the salt solution in the literature ranges between $2 \%$ to $5 \% \mathrm{NaCl}$ which is either used to increase the rate of corrosion or to simulate sea water environment. As for the position of the salt solution, the samples are sometimes completely immersed or partially. On the other hand, some authors mounted salt solution tanks on top of the concrete cover [Malumbela et al. 2010] or at the sides (Zhao et al. 2019). Finally, salt contamination by using towels (Qiu et al. 2019), sprinklers (Lu et al. 2018) or sponges (Torres-Acosta et al. 2007) were used.

For the present experiment, the set-up as shown in Figure 1 (right) was developed. Tanks filled with 5\% $\mathrm{NaCl}$ were placed on the concrete cover which facilitated measuring the evolution of corrosion cracks without the need to flip the beams every time. The cathode was in the form of a rectangular stainless steel plate which was placed inside the tank in direct contact with the cover and a current density of 100 $\mu \mathrm{A} / \mathrm{cm}^{2}$ was applied. The chosen current density was reasonable as it was not too high to cause excessive cracking as could happen for current densities above $200 \mu \mathrm{A} / \mathrm{cm}^{2}$ (El Maaddawy et al. 2003).

Six beams were corroded at the same time in the lab where a main power supply was used to distribute the current equally through current dividers. The target corrosion levels were 5\% (low), 10\% (medium) and $15 \%$ (high) mass loss for each two beams made from the same batch. During the corrosion process,

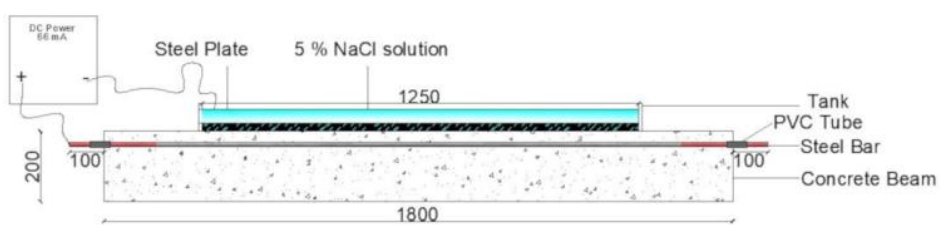

Figure 1. Beam section in mm (left), wooden moulds used for casting (middle), accelerated corrosion set-up (right). 
the experiment was stopped once per week to perform crack measurments which were done using a crack meter at $10 \mathrm{~cm}$ intervals along the beams. The naming of the beams is presented in Table 2 where the first character indicates the target mass loss, the second character indicates the type of the rebar (ribbed or smooth) while the third one indicated the copy of the beam.

Table 2. Nomenclature of corroded beams and target mass loss levels.

\begin{tabular}{|c|c|c|c|}
\hline \multirow{4}{*}{ Mass Loss } & & Ribbed & Smooth \\
\hline & $5 \%$ & $5 \mathrm{R} 1 \quad 5 \mathrm{R} 2$ & $5 \mathrm{~S} 1 \quad 5 \mathrm{~S} 2$ \\
\hline & $10 \%$ & 10R1 10R2 & $10 \mathrm{~S} 110 \mathrm{~S} 2$ \\
\hline & $15 \%$ & 15R1 15R2 & $15 \mathrm{~S} 115 \mathrm{~S} 2$ \\
\hline
\end{tabular}

\subsection{Rust cleaning and 3D scanning}

From the literature, it is clear that the chemical procedure according to ASTM G1-03 (ASTM Standard G01-03 2011) has been widely used. After the cleaning process, most authors sufficed with the obtained weight loss or the measured section or pit depth using manual measuring tool. Photogrametry (Cavaco et al. 2018) and 3D laser scanning have been employed to build 3D models of the corroded rebar which proved to be efficient in extracting data related to pit depth and shape.

For the present paper, the rebars were extracted from the concrete and cut into segments of $20 \mathrm{~cm}$. The length of the cut segments was measured so that the exact initial weight can be calculated based on the weight of a non-corroded rebar of known length. The cleaning process was done in cycles of 25 minutes according to the chemical treatment procedure C.3.1 of ASTM G1-03. When the rebar was inspected to be clean and the percentage difference between the last two cycles was constant, the cleaning process was stopped. After that, Nikon LC60Dx laser line scanner which was attached to a Coord3 MC16 coordinate measuring machine was used to create $3 \mathrm{D}$ models of the cleaned bars where four scans at a $90^{\circ}$ angle were performed.

\section{RESULTS}

\subsection{Concrete material properties}

The concrete compressive strength was tested by using three $150 \mathrm{~mm}$ cubes at 28 days and an additional three cubes on the day of the bending test for the beams that were corroded. Moreover, the flexural strength was tested using a three-point bending test on 150x150x600 mm prisms at 28 days.

The results of the compressive strength showed that at 28 days the average strength varied between $46 \pm 0.2 \mathrm{MPa}$ and $55 \pm 0.9 \mathrm{MPa}$ while the results beyond 28 days showed an increase in the values for all corroding batches which varied between $53 \pm 0.7$ $\mathrm{MPa}$ and $61 \pm 2.4 \mathrm{MPa}$. The results of the flexural strength ranged between $3.8 \pm 0.1 \mathrm{MPa}$ and $5.4 \pm 0.5$ MPa.

\subsection{Corrosion cracking}

Cracking and rust formation were noticed on the surfaces of the beams a week after the corrosion process except for beams 10R1 and 10R2 in which case the damage was noticed after two weeks because they were initially corroded at a rate of $50 \mu \mathrm{A} / \mathrm{cm}^{2}$ for 31 days and 32 days respectively after which the current density was increased to $100 \mu \mathrm{A} / \mathrm{cm}^{2}$. In all cases, initial rust spots formed at local positions as shown in Figure 2 which later spread along the full length of the contaminated cover. The rust spots exhibited a reddish color indicating the formation of $\mathrm{Fe}^{3+}$ ions. However sometimes a greenish color, indicating the presence of $\mathrm{Fe}^{2+}$ was spotted in the water which can be due to an insufficient supply of soluble oxygen.

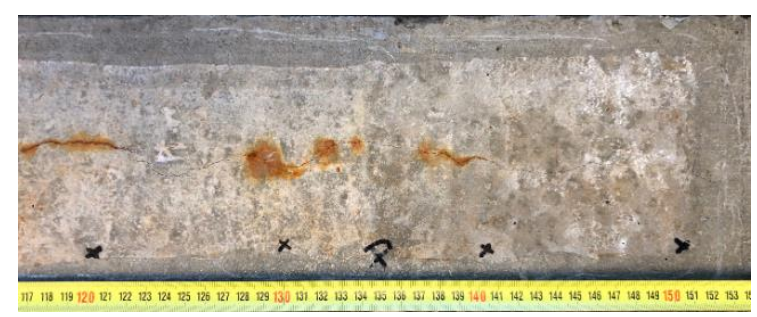

Figure 2. Local rust spots on beam 15R1 (picture taken after 18 days of the accelerated corrosion).

The crack measurements were done by three persons so as to minimize the errors related to visual inspection by a crack meter. The results showed that the first observed cracks for all beams were below 0.2 $\mathrm{mm}$. At the end of the corrosion duration, it was noticed that certain ranges of cracking can be assigned to the different corrosion levels (Figure 3 and Figure 4). For the beams with target corrosion level of $5 \%$, the range of cracking was between 0.3 $\mathrm{mm}$ and $0.6 \mathrm{~mm}(5 \mathrm{R} 1,5 \mathrm{R} 2,5 \mathrm{~S} 2)$ except for $5 \mathrm{~S} 1$ which showed cracks in the range between $0.6 \mathrm{~mm}$ and $1 \mathrm{~mm}$ corresponding to the medium corrosion level (10S1, 10S2 and 15R2). Furthermore, beams $10 \mathrm{R} 1$ and 10R2 showed some cracks that were slightly wider than $1 \mathrm{~mm}$ indicating that the beams either exceeded the medium corrosion level or just reached its upper bound (10\%). Thereafter, beams $15 \mathrm{R} 1,15 \mathrm{~S} 1$ and $15 \mathrm{~S} 2$ showed cracking in the range above $1 \mathrm{~mm}$ with widths reaching $1.6 \mathrm{~mm}, 1.4 \mathrm{~mm}$ and $1.6 \mathrm{~mm}$ respectively which is considered to be related to high level of corrosion damage.

From the cracking evolution graphs (Figure 5 and Figure 6), it is clear that beam 15R2 was corroding and cracking at a slower rate. This happened due to 
other types of measurements that were performed on the beam which lead to more frequent current interruptions. Beam 5S1 was cracking at a higher rate which can be explained by a higher corrosion rate.

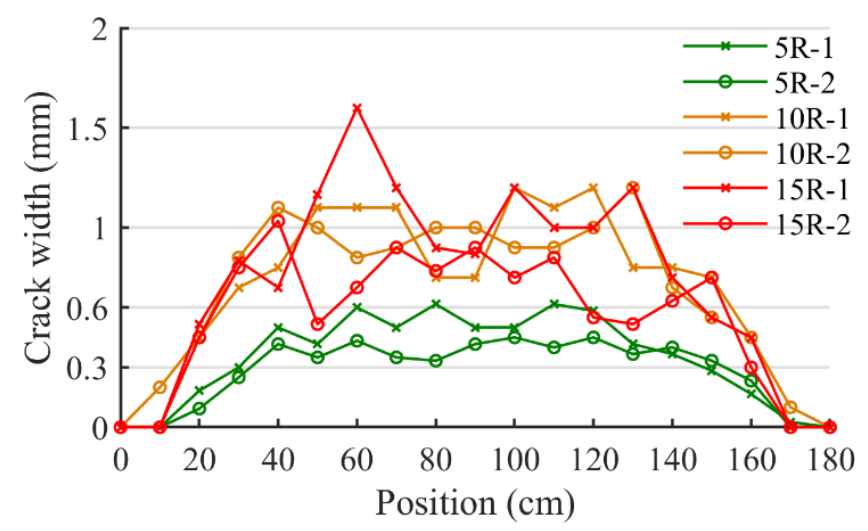

Figure 3. Crack profiles for beams with ribbed bars.

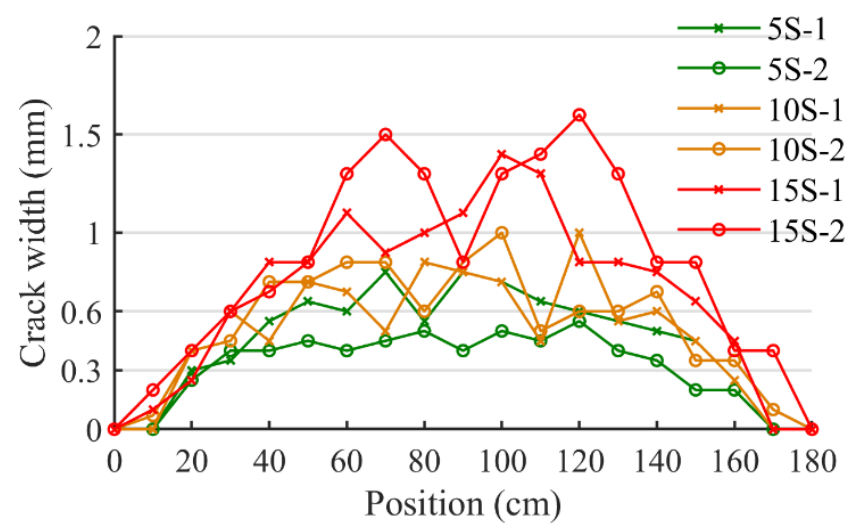

Figure 4. Crack profiles for beams with smooth bars.

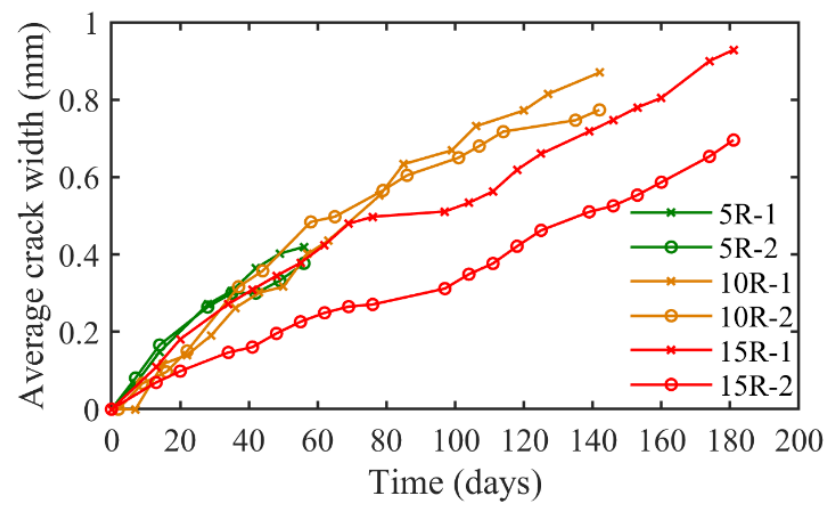

Figure 5. Average crack evolution for beams with ribbed bars.

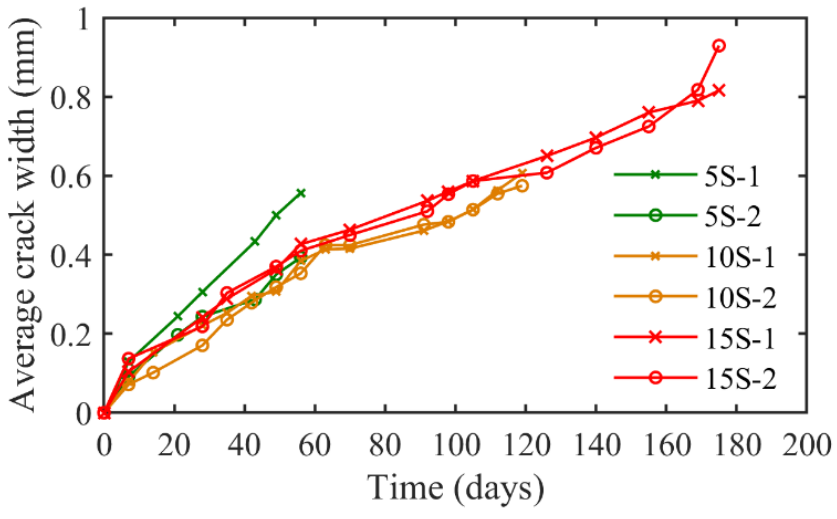

Figure 6. Average crack evolution for beams with smooth bars.

From the previous analysis, cracking ranges as a function of the corrosion level are defined in Table 3 for the maximum crack widths reached. It is also seen that for a certain corrosion level, some beams are more damaged. This can be observed through the wider cracks at multiple locations or by comparing the average crack widths.

Table 3. Cracking ranges for the current study based on maximum crack width measurements.

\begin{tabular}{lll}
\hline Level & Range $(\mathrm{mm})$ & Beams \\
Low & $0.3-0.6$ & 5R2 5R1 5S2 \\
Medium & $0.6-1.0$ & 5S1 10S1 10S2 15R2 \\
High & $>1.0$ & 10R1 10R2 15S1 15R1 \\
& & 15S2 \\
\hline
\end{tabular}

\subsection{Effective mass loss and pitting}

Results of Table 4 show the effective mass loss which were obtained by weighing and 3D scanning of the cleaned rebars. It was evident that the target mass loss was reached for the beams of low and medium corrosion level, with slight deviations in the order of $\pm 1 \%$. On the other hand, those of the high corrosion level (15\%) showed more variation where only $15 \mathrm{~S} 2$ reached the desired mass loss. Moreover, the results from the 3D scans showed a good agreement with those of the weighing where the difference between both measurement techniques reached was at most $1 \%$. Underestimations from the volume results of the 3D scans was a consequence of missing points in the point cloud due to failure of the laser to reach certain small pits or tiny corners in the corroded bars which resulted in holes in the polygon mesh. 
Table 4. Mass loss of the full rebar obtained from weighing and 3D scanning.

\begin{tabular}{llllll}
\hline Beam & $\begin{array}{l}\text { Weigh- } \\
\text { ing }\end{array}$ & $\begin{array}{l}\text { 3D } \\
\text { scan }\end{array}$ & Beam & $\begin{array}{l}\text { Weigh- } \\
\text { ing }\end{array}$ & 3D scan \\
5R1 & 4.6 & 4.9 & $5 \mathrm{~S} 1$ & 6.6 & 5.5 \\
$5 \mathrm{R} 2$ & 4.8 & 5 & $5 \mathrm{~S} 2$ & 5.5 & 4.5 \\
10R1 & 10.1 & 10.3 & $10 \mathrm{~S} 1$ & 8.9 & 8.1 \\
10R2 & 10.6 & 10.3 & $10 \mathrm{~S} 2$ & 9.3 & 9.4 \\
15R1 & 13.1 & 13.1 & $15 \mathrm{~S} 1$ & 13.6 & 12.7 \\
15R2 & 9.3 & 9.6 & $15 \mathrm{~S} 2$ & 16.0 & 15 \\
\hline
\end{tabular}

By examining the mass loss of the $20 \mathrm{~cm}$ segments, variations could be noticed along the rebar as in the case of 15S1 (Figure 7). By taking into account that the corrosion reaction was concentrated in the chloride-ingress region, the ratio of the segment with maximum mass loss $(20.8 \%)$ to the one with the smallest $(11.6 \%)$ can reach 1.8 (as shown in the results of 15S1). This indicates that some bar segments might have larger pits than other segments.

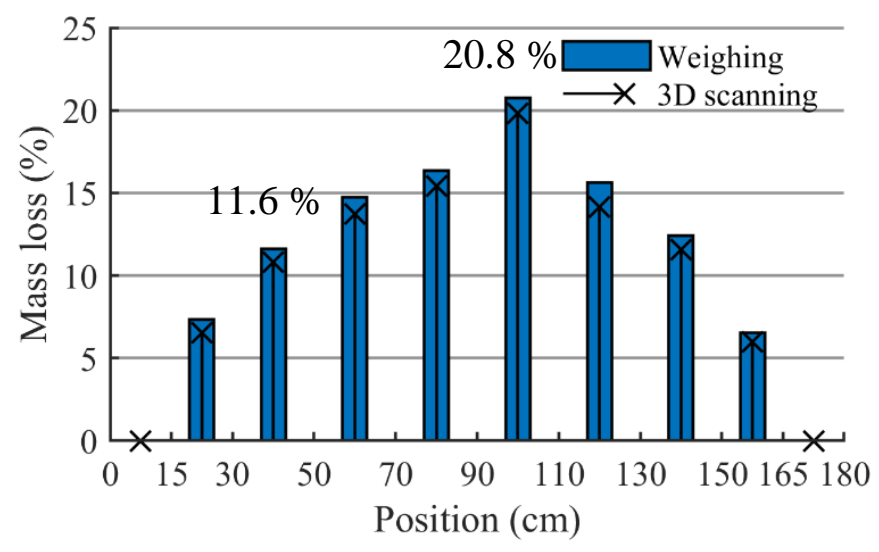

Figure 7. Variation of mass loss for beam 15S1 (chloride-ingress region being 30-110 cm).

The pitting corrosion was assessed through the pitting factor $(\alpha)$, which is defined as the ratio of the maximum radius loss to the average radius loss. The method for calculating it was as follows; at first, the segment with the maximum mass loss was sliced in Rhino3D into smaller segments of $5 \mathrm{~mm}$ using planes. Then, the minimum cross section of the segment with the smallest volume was obtained. The shape of the minumum residual cross-sections, for the case of segment 90-110 of beam 15S1, is shown in Figure 8. Because the contamination with salt solution was from one side, the radius loss was more severe at the rebar side facing the the water tank. The assumptions in Figure 9 are taken into account when calculating the radius losses. The average radius loss was calculated from the residual average cross-section of the full rebar which is $133 \mathrm{~mm}^{2}$. This gave $\mathrm{x}_{\mathrm{av}}=0.5$ $\mathrm{mm}$. On the other hand, the maximum radius loss was calculated from the area of the smallest residual section which was $108 \mathrm{~mm}^{2}$ (obtained from Rhino). After obtaining the corresponding minimum diameter, $\mathrm{x}_{\max }$ was calculated as the difference between the original diameter and the residual one. This resulted in $\mathrm{x}_{\max }=2.27 \mathrm{~mm}$ and consequently to a pitting factor of 4.5. Similar analysis showed that the pitting factor ranged between 3 and 4 for the other beams which confirms that the corrosion is nonuniform and variable along the length of the bar.

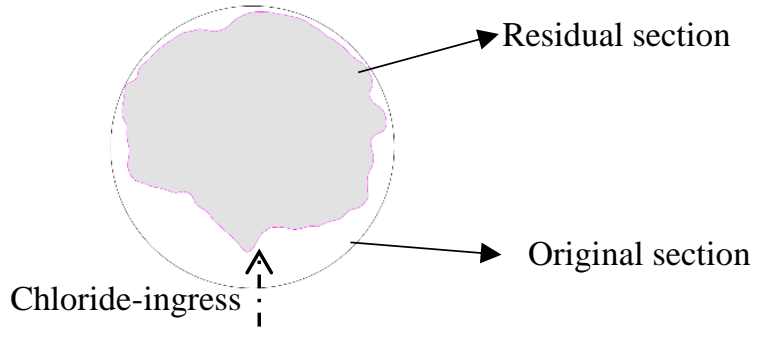

Figure 8. Shape of the minimum residual section along segment $[90-110 \mathrm{~cm}]$ of $15 \mathrm{~S} 1$.

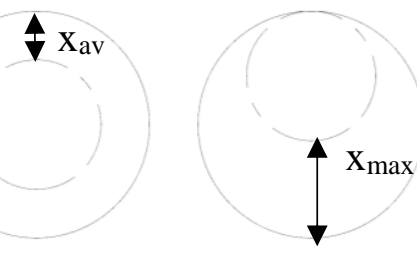

Figure 9. Average radius loss (left) and maximum radius loss (right).

\subsection{Section loss and damage relations}

The relation between the cracking and the rebar mass loss is important because the mass loss remains uncertain during inspection. Therefore, this section focuses on the link between the crack width and the section loss.

After analysing the mass loss results, classification of Table 5 showed the corresponding crack range to diffferent corrosion levels. The result which confirms the choice of the ranges when comparing the cracking profiles of section 3.2. Yet, the cracking ranges corresponding to each corrosion level depend on factors related to the concrete properties and the corrosion process which are discussed in the next sections.

Table 5. Corrosion levels and corresponding cracking ranges for the current study.

\begin{tabular}{lll}
\hline Corrosion level & Mass loss range & $\begin{array}{l}\text { Cracking range } \\
(\mathrm{mm})\end{array}$ \\
Low & $<5 \%$ & $0.3-0.6$ \\
Medium & $5-10 \%$ & $0.6-1$ \\
High & $>10 \%$ & $>1$ \\
\hline
\end{tabular}

In order to assess the relation between the crack width and the rebar section loss for this study, the average of three crack measurements, that corresponded to the $20 \mathrm{~cm}$ bar segment, was correlated to the mass loss results of that particular segment. A power function with two coefficients was 
used for the regression. The results of the regression analysis are provided in Figure 11.

They show good correlation for both the case of the ribbed and the smooth rebars. Moreover, both equations tend to a linear function with an approximate similar value of the multiplication coefficient. So, it can be considered that the cracking behavior of the beams with smooth bars is similar to that of the ribbed bars, and thereby a unified regression equation (1) was obtained by combining both data sets.

$$
\Delta \mathrm{A}=14 \mathrm{w}^{1.05}
$$

The curve showed that the cracking initiation, which is the corrosion period without visible damage on the surface, is negligible for the present experiment. However, under natural conditions, lower corrosion rates or in cases of large covers, a crack initiation period is present and can be expressed by shifting the curve upwards with a value $\Delta \mathrm{A}_{0}$. This value can be estimated from formulas found in the literature (Chen et al. 2018) or by predicting it from corrosion rate measurements.

As mentioned previously, there are factors that affect the cracking behaviour which have an effect on the empirical relation. In the next parts, the effect of these factors is studied and the developed relation (1) is compared to other calibrated relations from the literature.

At first, Figure 10 compares the behaviour of two accelerated corrosion experiments with singly reinforced beams and prisms to the current study. This is done by fitting a power relation to their experimental data. The obtained equations and the experimental conditions are presented in Table 6. It can be seen that a larger cover depth causes wider surface cracks at lower mass loss levels. The curve also shows an apparent crack initiation period, initial vertical curve, that reaches $2.9 \%$. Moreover, a lower current density with a cover-to-diameter ratio similar to the current study showed smaller cracks at higher mass loss levels. This suggests that it is important to take factors such as cover depth, rebar diameter and the corrosion rate into account while developing inspection-based relations.

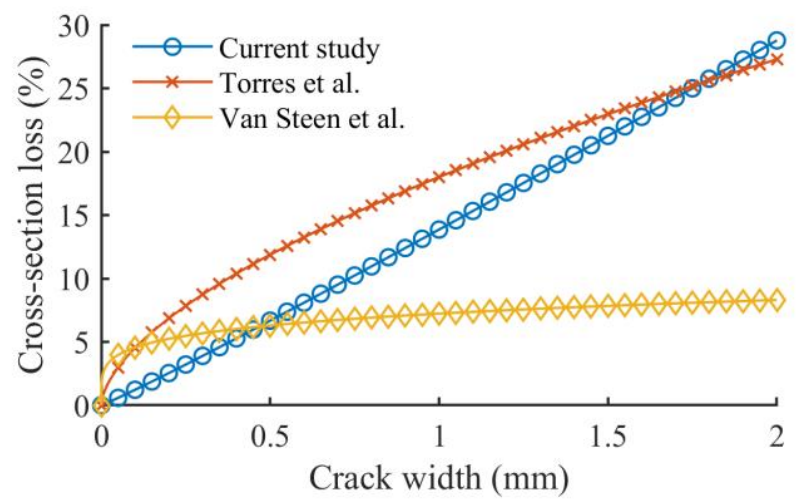

Figure 10. Concrete cover cracking under different corrosion rates and cover-to-diameter ratios.

Table 6. Details about the experiments of Fig. 10 (c=cover, $. \phi=$ rebar diameter, $\mathrm{i}=$ current density).

\begin{tabular}{lllll}
\hline Reference & Equation & $\begin{array}{l}\mathrm{c} \\
(\mathrm{mm})\end{array}$ & $\begin{array}{l}\phi \\
(\mathrm{mm})\end{array}$ & $\begin{array}{l}\mathrm{i} \\
\left(\mu \mathrm{A} / \mathrm{cm}^{2}\right) \\
100\end{array}$ \\
$\begin{array}{l}\text { Van Steen } \\
\text { et al. 2019 }\end{array}$ & $\Delta \mathrm{A}=7.2 \mathrm{w}^{0.2}$ & 69 & 12 & 100 \\
\hline $\begin{array}{l}\text { Torres- } \\
\begin{array}{l}\text { Acosta et } \\
\text { al. 2007 }\end{array}\end{array}$ & $\Delta \mathrm{A}=18 \mathrm{w}^{0.6}$ & 20 & 10 & 80 \\
\hline Current & $\Delta \mathrm{A}=14 \mathrm{w}^{1.05}$ & 30 & 14 & 100 \\
\hline
\end{tabular}

Next, the developed relation is compared to other empirical damage relations in the literature.These formulas relate the crack width to either the radius loss (according to equation 2) or to the cross-section loss. For the current study, the percentage cross-

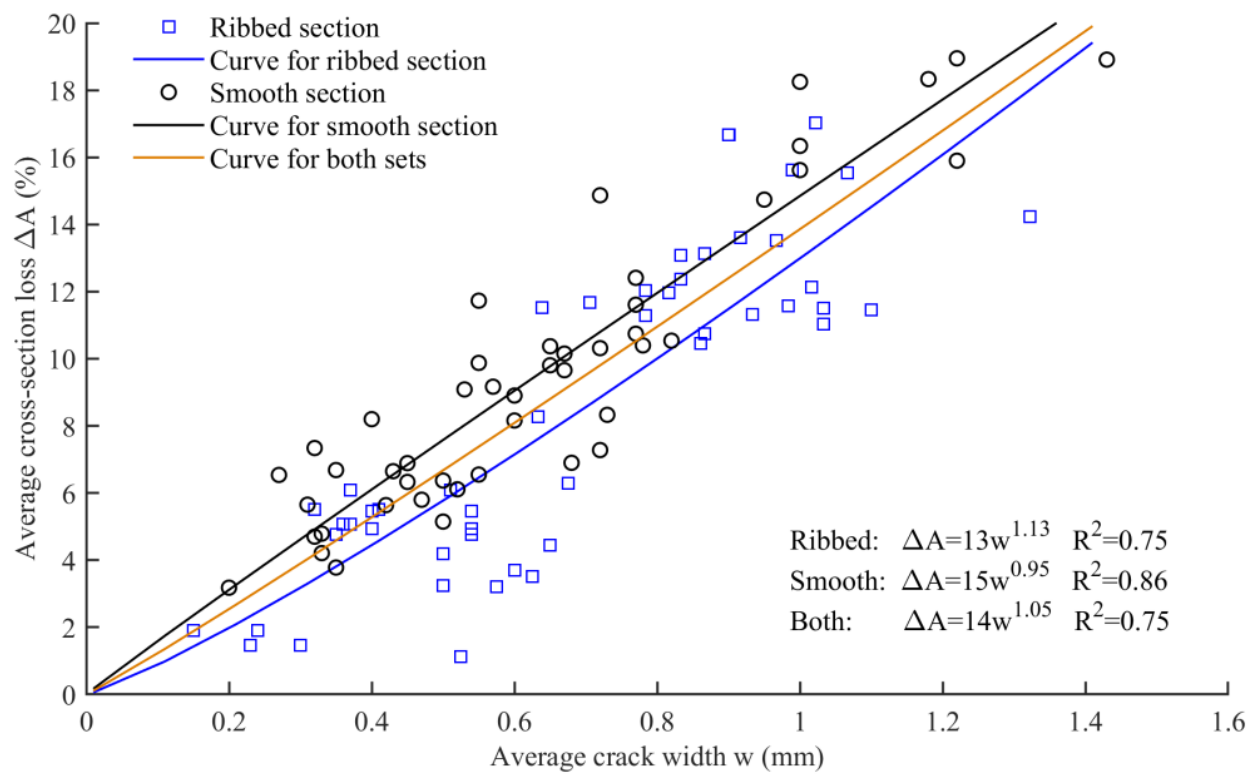

Figure 11. Correlation between the average crack width and the average cross-section loss. 
section loss was used to compare all the formulas as shown in Table 7. Therefore, the radius loss was converted to a cross-section loss by using equation (3).

$$
\begin{aligned}
& \mathrm{x}_{\mathrm{av}}=\frac{\Delta \mathrm{M} \text { (mass loss) }}{\rho(\text { density of steel }) \pi \mathrm{L}(\text { Length }) \phi_{\mathrm{o}}} \\
& \frac{\mathrm{x}_{\mathrm{av}}}{\mathrm{r}_{\mathrm{o}}}=0.5 \frac{\Delta \mathrm{A}}{\mathrm{A}}
\end{aligned}
$$

In addition to that, most expressions in the literature regressed the crack width to the crosssection loss while in this study the reverse was made because it is assumed that during an inspection the cross-section loss will be predicted through the crack width measurement. So, the literature formulas are plotted similarly to the current study. After plotting the literature data from their original equations against the percentage cross-section loss, regression analysis was used to obtain the equation of the curve in the format of the current study. It is worth mentioning that since the crack initiation period was very short, related parameters in the formulas were also neglected in this study.

An overview of the converted equations is shown in Table 7, in which the effect of the different parameters ( c, $\phi$ and i, see Table 6) is studied. The comparison of the equations of the natural corrosion experiments show that they underestimated the behaviour of the current experiment. This is attributed to the fact that corrosion products under natural conditions have a larger expansion ratio than those subjected to impressed current. However, the model by Vidal showed closer results to those of the accelerated corrosion even though the beams used were similar to those by Khan and Zhang. But, the crack measurements were done during a stage when they were corroding under wetting and drying cycles which might have produced corrosion products of lower expansion ratio (Khan et al. 2014). This shows that it is important to take into account the environmental conditions and the possible formed corrosion products in the empirical models.

Additionally, the results of the models of the accelerated corrosion experiments show difference in predictions. The model of Torres-Acosta only slightly overestimated. This is due to the lower current density that was used given that the beams and the cover-todiameter ratio were similar to the current study. On the other hand, the models by Andrade and Rodriguez underestimated the behavior. Even though the one by Andrade takes into account the cover depth, rebar diameter and the concrete tensile strength. The calibration is done on large data sets with different conditions and corrosion rates which are not considered. Finally, the model of Rodriguez depends on the pitting factor which only showed behavior close to that of the current study with a value of 10 . Yet, it was calculated earlier that $\alpha$ has a value of 4 . This underestimation could also be due to the different reinforcement layout because having multiple rebars and stirrups affect the cracking.

\begin{tabular}{|c|c|c|c|c|}
\hline & Reference & Original equation & Converted equation & Conditions \\
\hline \multirow[t]{6}{*}{ Accelerated } & Current & $\Delta \mathrm{A}(\%)=14.0 \mathrm{w}^{1.05}$ & - & $\begin{array}{l}\text { Current } \mathrm{i}=100 \mu \mathrm{A} / \mathrm{cm}^{2} \\
\text { Singly reinforced section with one } \\
\text { ribbed or smooth bars without stirrups. } \\
\mathrm{c} / \phi=2.1\end{array}$ \\
\hline & $\begin{array}{l}\text { Torres-Acosta } \\
\text { et al. } 2007\end{array}$ & $\mathrm{w}=6.4\left(\frac{\mathrm{x}_{\mathrm{av}}}{\mathrm{r}_{\mathrm{o}}}\right)^{0.82}$ & $\Delta \mathrm{A}(\%)=17 \mathrm{w}^{1.2}$ & $\begin{array}{l}\text { Calibrated on several experimental data } \\
\text { Singly reinforced section, } c / \phi=2\end{array}$ \\
\hline & $\begin{array}{l}\text { Andrade et al. } \\
2016\end{array}$ & $\mathrm{w}=15.863\left(\mathrm{x}_{\mathrm{av}} C T / \mathrm{r}_{\mathrm{o}}\right)^{0.928}$ & $\Delta \mathrm{A}(\%)=6.04 \mathrm{w}^{1.1}$ & $\begin{array}{l}\text { Calibrated on several experimental data } \\
10 \mu \mathrm{A} / \mathrm{cm}^{2}<\mathrm{i}<100 \mu \mathrm{A} / \mathrm{cm}^{2} \\
\text { Factor } C T=1.41(\mathrm{c} / \phi)^{0.63 / \mathrm{f}_{\mathrm{ct}}} \\
\mathrm{f}_{\mathrm{ct}} \text { : tensile strength of concrete }\end{array}$ \\
\hline & $\begin{array}{l}\text { Rodriguez et al. } \\
\alpha=2\end{array}$ & \multirow{3}{*}{$\begin{array}{l}\mathrm{W}=0.05+0.0125\left(\mathrm{x}-\mathrm{x}_{\mathrm{o}}\right) \\
\mathrm{x}=\phi_{\mathrm{o}} / \alpha(1-\sqrt{1-\Delta \mathrm{A} / \mathrm{A}}) \\
\mathrm{x}_{\mathrm{o}} \text { : radius loss to cause } \\
\text { surface cracking }\end{array}$} & $\Delta \mathrm{A}(\%)=2.3 \mathrm{w}$ & \multirow{3}{*}{$\begin{array}{l}\text { Impressed current } \mathrm{i}=100 \mu \mathrm{A} / \mathrm{cm}^{2} \\
\text { Doubly reinforced section with stirrups } \\
{[\mathrm{c} / \phi=0.8-1]}\end{array}$} \\
\hline & $\begin{array}{l}\text { Rodriguez et al. } \\
\alpha=4\end{array}$ & & $\Delta \mathrm{A}(\%)=4.5 \mathrm{w}$ & \\
\hline & $\begin{array}{l}\text { Rodriguez et al. } \\
\alpha=10\end{array}$ & & $\Delta \mathrm{A}(\%)=11 \mathrm{w}$ & \\
\hline \multirow[t]{2}{*}{ Natural } & $\begin{array}{l}\text { Zhang, Ruijin et } \\
\text { al. } 2010\end{array}$ & $\begin{array}{l}\mathrm{W}=0.1916 \Delta \mathrm{A}_{\mathrm{s}}+0.164 \\
\Delta \mathrm{A}_{\mathrm{s}}: \text { average cross-section } \\
\text { loss in } \mathrm{mm}^{2}\end{array}$ & $\Delta \mathrm{A}(\%)=3.4 \mathrm{w}$ & $\begin{array}{l}14 \text { and } 23 \text { years in salt fog environment } \\
\text { Two doubly reinforced sections with } \\
\text { stirrups }[\mathrm{c} / \phi=0.83]\end{array}$ \\
\hline & $\begin{array}{l}\text { Khan et al. } \\
2014\end{array}$ & $\mathrm{~W}=0.1916 \Delta \mathrm{A}_{\mathrm{s}} \phi / \mathrm{c}+0.164$ & $\Delta \mathrm{A}(\%)=7.2 \mathrm{w}$ & $\begin{array}{l}26 \text { years in salt fog environment } \\
\text { Doubly reinforced section with stirrups } \\
\text { [c/ } \phi=2.5 \text { ] } \\
\text { Modified from Zhang et al. } \\
\text { Factor: } \phi / c\end{array}$ \\
\hline
\end{tabular}

Table 7. Comparison between different damage models from literature. 
Vidal et al.

2004
$\mathrm{W}=0.0575\left(\Delta \mathrm{A}_{\mathrm{s}}-\Delta \mathrm{A}_{\mathrm{o}}\right)$

$\Delta \mathrm{A}(\%)=11.3 \mathrm{w}$

14 and 17 years in salt fog environment.

Two doubly reinforced sections with stirrups $\left[\mathrm{c}_{1} / \phi_{1}=0.83, \mathrm{c}_{2} / \phi_{2}=2.5\right]$.

\section{CONCLUSION}

The paper presented the cracking behavior of corroded RC beams. It can be concluded from the results that classification to corrosion levels can be performed based on corrosion crack profiles of the beams. Additionally, empirical relations linking the crack width to the cross-section loss are useful during inspection. Although several relations were developed, they seem to only reflect the experimental data upon which they were calibrated. Therefore, even though the inclusion of cover depth and rebar diameter in the damage models is a good approach, a greater efficiency in prediction requires the inclusion of other factors such as, the cross-section layout, concrete properties and corrosion conditions.

\section{REFERENCES}

Andrade, C., Cesetti, A., Mancini, G. and Tondolo, F., 2016, Estimating corrosion attack in reinforced concrete by means of crack opening. Structural Concrete, 17(4): 533-540.

ASTM Standard G01-03, 2011, Standard Practice for Preparing, Cleaning, and Evaluating Corrosion Test Specimens, ASTM International.

Cavaco, E., Pimenta, R. and Jonatas, V., 2018, A new method for corrosion assessment of reinforcing bars based on closedrange phtogrammetry: Experimental validation. Structural Concrete, 20(2019): 996-1001.

Chen, F., Baji, H. and Li, C.-Q., 2018, A comparative study on factors affecting time to cover cracking as a service life indicator. Construction and Building Materials, 163(2018): 681-694.

CONTECVET, A validated user's manual for assessing the residual service life of concrete structures,

El Maaddawy, T. and Soudki, K., 2003, Effectiveness of impressed current technique to simulate corrosion of steel reinforcement in concrete. Journal of Materials in Civil Engineering, 15(1): 41-47.

Khan, I., François, R. and Castel, A., 2014, Prediction of reinforcement corrosion using corrosion induced cracks width in corroded reinforced concrete beams. Cement and Concrete Research, 56(2014): 84-96.

Lu, Y., Tang, W., Li, S. and Tang, M., 2018, Effects of simultaneous fatigue loading and corrosion on the behavior of reinforced beams. Construction and Building Materials, 181(2018): 85-93.

Malumbela, G., Alexander, M. and Moyo, P., 2010, Lateral deformation of RC beams under simultaneous load and steel corrosion. Construction and Building Materials, 24(1): 1724.

Malumbela, G., Moyo, P. and Alexander, M., 2012, A step towards standardising accelerated corrosion tests on laboratory reinforced concrete specimens. Journal of the South African Institution of Civil Engineering, 54(2): 78-85.
Nasser, H., Van Steen, C., Vrijdaghs, R., Torres-Acosta, A. A., Vandewalle, L. and Verstrynge, E., 2019, Numerical modelling of corroded reinforced concrete beams based on visual inspection data, 5th SMAR conference, Potsdam.

Qiu, J., Zhang, H., Zhou, J., Ma, H. and Liao, L., 2019, Experimental analysis of the correlation between bending strength and SMFL of corroded RC beams. Construction and Building Materials, 214(2019): 594-605.

Rodriguez, J., Ortega, L., Izquierdo, D. and Andrade, C., 2006, Calculation of structural degredation due to corrosion of reinforcement, Springer.

Torres-Acosta, A. A., Navarro-Gutierrez, S. and Terán-Guillén, J., 2007, Residual flexural capacity of corroded reinforced concrete beams. Engineering Structures, 29(6): 1145-1152.

Van Steen, C., Verstrynge, E., Wevers, M. and Vandewalle, L., 2019, Assessing the bond behaviour of ribbed and smooth rebars with acoustic emission monitoring. Cement and Concrete Composites, 120(2019): 176-186.

Vidal, T., Castel, A. and François, R., 2004, Analyzing crack width to predict corrosion in reinforced concrete. Cement and Concrete Research, 34(1): 165-174.

Zhang, R., Castel, A. and François, R., 2010, Concrete cover cracking with reinforcement corrosion of RC beam during chloride-induced corrosion process. Cement and Concrete Research, 40(3): 415-425.

Zhang, W., Chen, J. and Luo, X., 2019, Effects of impressed current density on corrosion induced cracking of concrete cover. Construction and Building Materials, 204(2019): 213-223.

Zhao, P., Xu, G., Wang, Q. and Tang, G., 2019, Influence of sustained load on corrosion characteristics of reinforced concrete beams under galvanostatic accelerated corrosion. Construction and Building Materials, 215(2019): 30-42.

Zhu, W. and François, R., 2014, Corrosion of the reinforcement and its influence on the residual structural performance of a 26-year-old corroded RC beam. Construction and Building Materials, 51(2014): 461-472. 